\title{
高密度 $\mathrm{CO}_{2}$ による $\alpha$-トコフェロールの抽出に対する エタノールおよび $\mathrm{H}_{2} \mathrm{O}$ のエントレーナ効果 ${ }^{\dagger}$
}

\author{
大垣一成・西川 亮*.古市 正 $^{* *}$. 片山 俊 \\ 大阪大学基礎工学部 化学工学科
}

\begin{abstract}
本研究では, 超臨界流体抽出のエントレーナ効果に注目し, 先に報告した $\boldsymbol{\alpha}$-トコフェ ロール - $\mathrm{CO}_{2}$ 系に対して $\mathrm{H}_{2} \mathrm{O}$ あるいはエタノールを添加することにより, 各 3 成分系の高 圧相平衡関係がどのように変化するかを実験的に検討した.

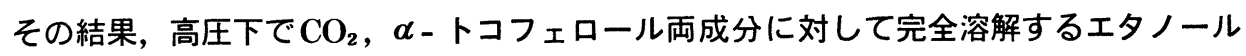
をエントレーナとした場合, エタノールの添加量に対応して 2 相分離領域がせまくなり,

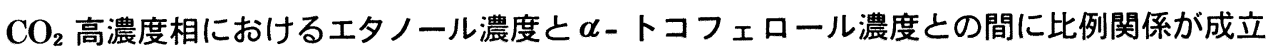
する領域があることが確認された.
\end{abstract}

\section{緒 言}

超臨界流体を利用した高圧分離技術に関する研究は, 様々な分野の企業を始め大学・研究所などで数多く行わ れている. 本技術の応用あるいは新展開にとって，その 鍵を握るのが溶解度の増加や選択性の向上をもたらすエ ントレーナの探索, ならびにエントレーナ効果の因子に ついての解明であると言っても過言ではないい

本来, 超臨界流体抽出 (以降 SFEと省略) に抢いて $\mathrm{CO}_{2}$ を溶媒とした場合, 人体に対する溶媒の有毒性の面 で安全であるという長所を損なわないためにも， $\mathrm{H}_{2} \mathrm{O} や$ エタノールがエントレーナとして利用できることが望ま しい.

本研究ではてうした点を考慮して, 先に報告した $\alpha$ トコフェロール (通称ビタミン $\mathrm{E}$ ) $-\mathrm{CO}_{2} 2$ 成分系 ${ }^{6}$ に対 して, $\mathrm{H}_{2} \mathrm{O}$ およびエタノールを第 3 成分とする各 3 成分 系の高圧相平衡関係を実測した。 $\mathrm{H}_{2} \mathrm{O}$ は本実験範囲で $\alpha$ 一トコフェロール, $\mathrm{CO}_{2}$ 両成分に対して大きな相分離領 域を持ち, 3 成分系の相平衡関係でも広い 3 相分䧻の存 在が予測される.一方, エタノールは両成分に対して完 全溶解することから， $\alpha$-トコフェロール $-\mathrm{CO}_{2} 2$ 成分 系の相分離領域を狭めることが考えられる．乙うした性

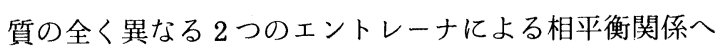
の影響を検討することは熱力学的にも興味深い.

\footnotetext{
† 1987 年 5 月 29 日受理 ; 化学工学協会第 52 年会 (名古屋, 1987年 4 月）にて発表

†† 560 豊中市待兼山町 $1-1$

* (株) クラレ

** (株) 山武八ネウェル
}

\section{1. 実験装置および方法}

本研究で作製した実験装置は，流通式で基本的には先 に報告したもの ${ }^{5,6)}$ と同様である. 改良点としては, 本研 究で取り扱う混合系の場合, 相挙動を観察する必要があ り, 高圧容器全体が見通せるように縦 $16 \mathrm{~cm}$, 横 $1.2 \mathrm{~cm}$ の 空が取り付けてある. また内容積は約 $100 \mathrm{~cm}^{3}$, 耐圧 30 $\mathrm{MPa}$, 最高使用温度は $60^{\circ} \mathrm{C}$ である.内容積はあらかじ め $\mathrm{H}_{2} \mathrm{O}$ で検定しておき, 界面の位置から各相の容積が約 $5 \%$ の誤差で求まるようにした。高圧容器の䚌拌には永 久磁石を用いた。温度, 圧力の測定方法は先に報告した もの 5 と同一である.

\section{1. $1 \mathrm{H}_{2} \mathrm{O}-\mathrm{CO}_{2} 2$ 成分系の測定方法}

$\mathrm{H}_{2} \mathrm{O}-\mathrm{CO}_{2} 2$ 成分系の $\mathrm{CO}_{2}$ 高濃度相における $\mathrm{H}_{2} \mathrm{O}$ の 組成分析は, 次のような手順で行った。平衡状態にある 混合流体を膨張バルブで減圧し，その後 $\mathrm{CO}_{2}$ のモル数は ガスメータで測定した．膨張バルブのすぐ後ろには，過 塩素酸マグネシュウム $(8 \sim 24 \mathrm{mesh})$ を充填した水分析 用サンプラーを取り付け, $\mathrm{H}_{2} \mathrm{O}$ を吸収させ重量分析した. 予備実験でモル数既知の $\mathrm{H}_{2} \mathrm{O}$ を使って吸収能力を調べた ところ， $\mathrm{H}_{2} \mathrm{O}$ が過塩素酸マグネシュウムの質量の約 $5 \%$ 以下であれば, $99 \%$ 以上の $\mathrm{H}_{2} \mathrm{O}$ が分析用サンブラーに吸 収されるととを確認した。

\section{2 エントレーナ成分を含む $\alpha$-トコフェロール - $\mathrm{CO}_{2}$ 混合系の測定方法}

$\alpha$-トコフェロール $-\mathrm{H}_{2} \mathrm{O}-\mathrm{CO}_{2} 3$ 成分系の場合, 乙 の系が 3 相に分離するため温度および圧力を固定すると 平衡状態が自動的に定まる. したがって, 各成分の適当 量 ( 3 相共存範囲内に対応する) を高圧容器に仕込み $\mathrm{CO}_{2}$ で加圧した後挸拌し, 圧力が一定となったところで 
平衡状態と見なした． $\mathrm{CO}_{2}$ のみを供給する本流通法では 厳密には平衡状態を実測することは困難である。 そこで, 先に報告したように ${ }^{6)}$, 平衡状態にある混合流体の高圧 容器上層部 $\left(\mathrm{CO}_{2}\right.$ 高濃度相) だけを, 圧力は一定に保っ た状態で少量取り出し，その組成を平衡組成とした.

また $\alpha$-トコフェロールーエタノール - $\mathrm{CO}_{2} 3$ 成分系の 場合， 2 相の平衡関係が成立するため, 温度と圧力の他 にあうひとつの自由度を固定すれば平衡状態が定まる。

したがって本実験では $\alpha$-トコフェロールとエタノールの 最初の仕込モル比を約 $1 / 3$ 一定として, 総仕込量の違う 2 通りの混合系を用いて溶解度実験を行った. 各総仕込 量について約 $10,13,16 \mathrm{MPa}$ の 3 通りの圧力での溶解度 を引続き測定するため, エ夕ノールが咸少し $\alpha$-トコフ エロールとエタノールのモル比は $1 / 3(10 \mathrm{MPa})$ から $2 / 5$ $(16 \mathrm{MPa})$ 一と変化した. 乙てで, モル比の変化は各圧 力に抢ける溶解度測定の際流出したエタノール， $\alpha$ ートコ フェロールの量を最初の仕込量から差し引いて求めた。

最後に高圧容器に残っている $\mathrm{CO}_{2}$ をガスメータを通して すべて放出し, そのモル数を測定した. 最後の状態（約 $16 \mathrm{MPa}$ )の仕込組成と液相の平衡組成とを両相の容積か ら求めた。な掖相の平衡組成の計算では混合気体の モル容積は $\mathrm{CO}_{2}$ のモル容積に等しいと仮定した.

๔-トコフェロールとエタノールあるいは $\mathrm{H}_{2} \mathrm{O}$ とからな

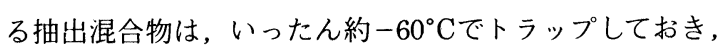
溶解度実験終了後, 乾燥窒素ガスを緩やかに流すととに よりエタノールあるいは $\mathrm{H}_{2} \mathrm{O}$ のみをサンプラーから流出 させ， $\alpha$-トコフェロールと分離させた. $\mathrm{H}_{2} \mathrm{O}$ の場合は 上記分析サンプラーを使い, エタノールは $-60^{\circ} \mathrm{C}$ 冷媒 中に浸した容器内にトラップした，窒素ガスで分離する 前後の重量分析の結果, いずれの場合む試料の系外への 流出はなかった。また予備実験でそれぞれ組成既知の混 合物を同様の手順で分離した結果， $\alpha$-トコフェロール - $\mathrm{H}_{2} \mathrm{O}$ 混合系では $1 \sim 2 \%$ の㕵差, また $\alpha$-トコフェロー ルーエタノール混合系では $5 \%$ 内の誤差で一致した.

試薬溶媒成分として使用した $\mathrm{CO}_{2}$ は高千穂化学 (株) 製の純度 $99.95 \mathrm{~mol} \%$ 以上のあのである. また $\mathrm{H}_{2} \mathrm{O}$ は 脱イオン水を蒸留したものを用い， $\alpha$-トコフェロール およびエタノールは $99.5 \mathrm{~mol} \%$ 以上の和光純薬製特級試 薬を使用した。

\section{2. 結果および考察}

\section{$2 \cdot 1 \mathrm{H}_{2} \mathrm{O}-\mathrm{CO}_{2} 2$ 成分系}

本実験範用でての混合系は 2 液相分蓶が成立しており, $25^{\circ} \mathrm{C}$ および $40^{\circ} \mathrm{C}$ における $\mathrm{CO}_{2}$ 高濃度相の $\mathrm{H}_{2} \mathrm{O}$ のモル分 率を各圧力に対して測定した結果をTable 1 亿示す.乙 の混合系を取り上げた理由は, 本系が 3 成分系の構成 2
Table 1 Mole fraction of $\mathrm{H}_{2} \mathrm{O}$ in $\mathrm{CO}_{2}$ rich phase for $\mathrm{H}_{2} \mathrm{O}-\mathrm{CO}_{2}$, system

\begin{tabular}{|c|c|c|}
\hline Temperature & $P[\mathrm{MPa}]$ & $y_{\mathrm{H}_{2} \mathrm{O}} \times 10^{3}[-]$ \\
\hline \multirow{8}{*}{$25^{\circ} \mathrm{C}$} & 7.86 & 3.42 \\
\hline & 7.88 & 3.23 \\
\hline & 9.75 & 3.35 \\
\hline & 9.77 & 3.39 \\
\hline & 12.3 & 3.52 \\
\hline & 12.3 & 3.47 \\
\hline & 14.7 & 3.47 \\
\hline & 14.7 & 3.43 \\
\hline \multirow{8}{*}{$40^{\circ} \mathrm{C}$} & 7.85 & 2.65 \\
\hline & 7.86 & 2.65 \\
\hline & 9.93 & 4.17 \\
\hline & 9.95 & 4.34 \\
\hline & 12.3 & 4.75 \\
\hline & 12.3 & 4.77 \\
\hline & 14.7 & 5.09 \\
\hline & 14.7 & 5.21 \\
\hline
\end{tabular}

成分系の一つであるとと, 文献值が報告されているので 装置の健全性を検討できることなどである.

本系の $25^{\circ} \mathrm{C}$ に打ける相平衡関係は Wiebe と Gaddy $y^{8}$ に よって報告されているので, 本研究で得られた結果と比 較してFig. 1 亿示す. $25^{\circ} \mathrm{C}$ 亿扔ける両者の值は実験䛊差 内で一致した. $\mathrm{H}_{2} \mathrm{O}-\mathrm{CO}_{2}$ 2 成分系の相挙動の特徵とし ては, $25^{\circ} \mathrm{C}$ で $6 \mathrm{MPa}$ 付近に付加的な気液共存領域が存 在し, $40^{\circ} \mathrm{C}, 7 \mathrm{MPa}$ 付近に溶解度の大きな圧力依存性が 確認されたてとである. 実験結果をSRK状態方程式 ${ }^{7)}$ 用いて相関したとてろ，2成分系定数 $k_{12}$ は $25^{\circ} \mathrm{C}, 40^{\circ} \mathrm{C}$ でそれぞれ0.1534, 0.1503 の值となり，Fig. 1 中に示す ようにほぼ満足のいく結果が得られた。

\section{$2 \cdot 2 \alpha$ - トコフェロール $-\mathrm{H}_{2} \mathrm{O}-\mathrm{CO}_{2} 3$ 成分系}

この系の $25^{\circ} \mathrm{C}, 40^{\circ} \mathrm{C}$ に打ける実験結果はTable 2 亿ま とめて示し, $\mathrm{CO}_{2}$ との 2 成分系における ルおよび $\mathrm{H}_{2} \mathrm{O}$ の溶解度と比較して Figs. 2, 3 に示す. 3 成分系の $\mathrm{H}_{2} \mathrm{O}$ の溶解度は $\mathrm{H}_{2} \mathrm{O}-\mathrm{CO}_{2} 2$ 成分系の $\mathrm{H}_{2} \mathrm{O}$ の それと比較して, どちらの温度であわずかに減少し， 3 成分系の $\alpha$-トコフェロールの溶解度についても $25^{\circ} \mathrm{C}$ てわ

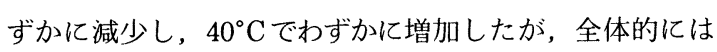
$\alpha$-トコフェロールおよび $\mathrm{H}_{2} \mathrm{O}$ の溶解度とも, $\mathrm{CO}_{2}$ との 2 成分系に打けるそれと大きな变化はみられなかった。

$\mathrm{CO}_{2}$ 高濃度相に打ける $\mathrm{H}_{2} \mathrm{O}$ の濃度か非常に小さいととと， $\alpha$-トコフェロール $-\mathrm{H}_{2} \mathrm{O}$ 混合系の場合, 乙の温度, 仕 込組成で液液分離が生じていることから， $\alpha$-トコフェ口 ールー $\mathrm{H}_{2} \mathrm{O}$ 混合系に抢りる $\alpha$-トコフェロールの分圧は 純粋状態の飽和蒸気圧とほとんど等しいことなどにより， 各構成 2 成分系に打けるそれぞれの $\mathrm{CO}_{2}$ への溶解度に大 


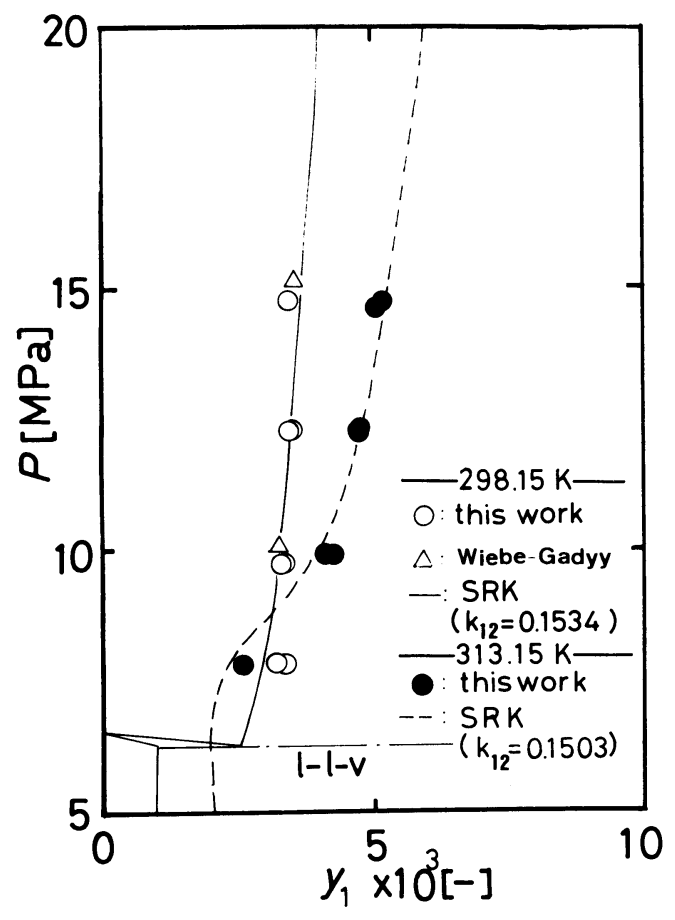

Fig. $1 P-y$ isotherms of $\mathrm{H}_{2} \mathrm{O}(1)-\mathrm{CO}_{2}(2)$ system at $25^{\circ} \mathrm{C}$ and $40^{\circ} \mathrm{C}$

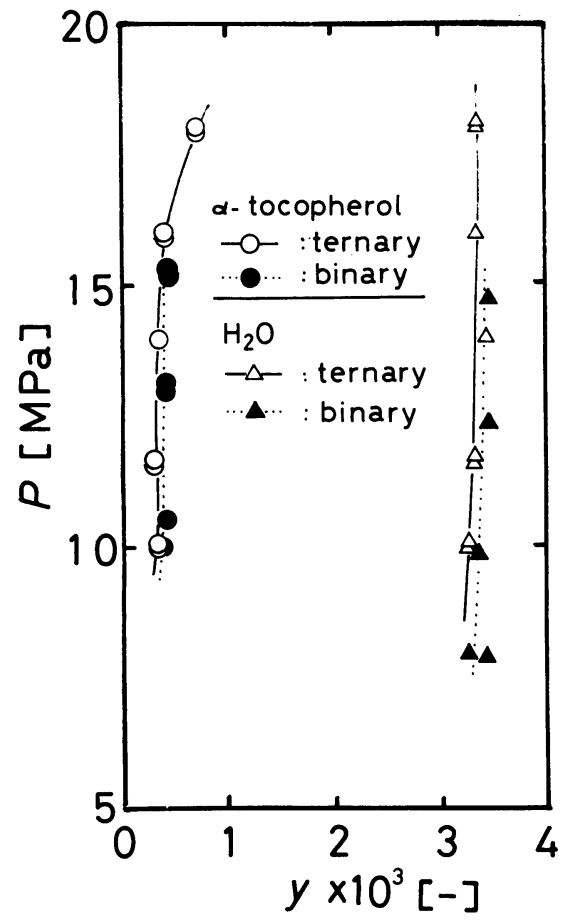

Fig. $2 P-y$ relations of ternay $\alpha$-tocopherol (A) $-\mathrm{H}_{2} \mathrm{O}(\mathrm{B})-\mathrm{CO}_{2}(\mathrm{C})$ system and binary $\mathrm{H}_{2} \mathrm{O}-\mathrm{CO}_{2}$ and $\alpha$-tocopherol $-\mathrm{CO}_{2}$ systems at $25^{\circ} \mathrm{C}$

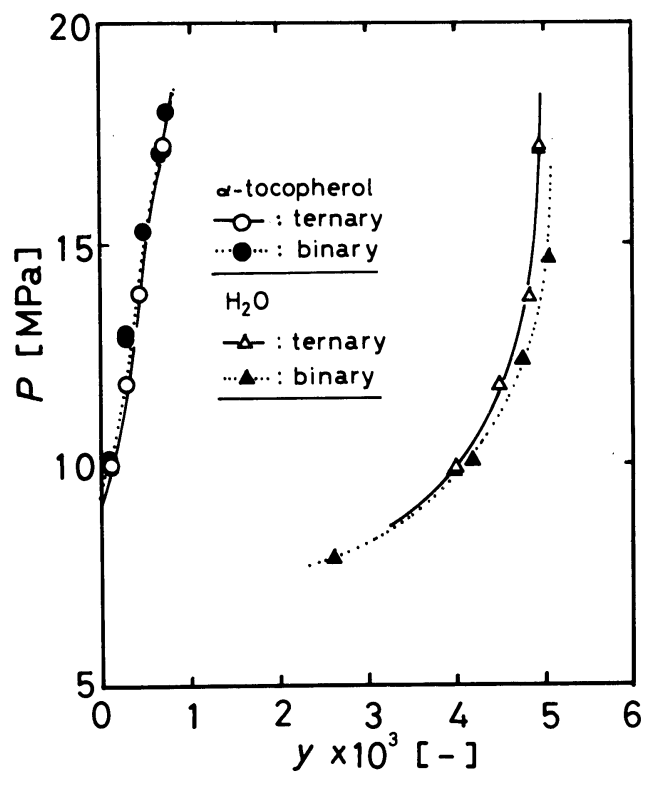

Fig. $3 P-y$ relations of ternary $\alpha$-tocopherol (A) $-\mathrm{H}_{2} \mathrm{O}(\mathrm{B})-\mathrm{CO}_{2}(\mathrm{C})$ system and binary $\mathrm{H}_{2} \mathrm{O}-\mathrm{CO}_{2}$ and $\alpha$-tocopherol $-\mathrm{CO}_{2}$ systems at $40^{\circ} \mathrm{C}$

Table 2 Mole fractions of $\alpha$-tocopherol and $\mathrm{H}_{2} \mathrm{O}$ in $\mathrm{CO}_{2}$-rich phase for $\alpha$-tocopherol(A) $\mathrm{H}_{2} \mathrm{O}(\mathrm{B})-\mathrm{CO}_{2}(\mathrm{C})$ system

\begin{tabular}{|c|c|c|c|}
\hline Temperature & $P[\mathrm{MPa}]$ & $y_{\mathrm{A}} \times 10^{4}[-]$ & $y_{\mathrm{B}} \times 10^{3}[-]$ \\
\hline \multirow{9}{*}{$25^{\circ} \mathrm{C}$} & 9.88 & 3.23 & 3.19 \\
\hline & 9.95 & 3.55 & 3.20 \\
\hline & 11.6 & 2.78 & 3.18 \\
\hline & 11.8 & 2.70 & 3.31 \\
\hline & 14.0 & 3.56 & 3.48 \\
\hline & 15.9 & 3.92 & 3.42 \\
\hline & 15.9 & 4.02 & 3.31 \\
\hline & 17.9 & 7.52 & 3.51 \\
\hline & 17.9 & 7.49 & 3.35 \\
\hline \multirow{6}{*}{$40^{\circ} \mathrm{C}$} & 9.86 & 1.09 & 3.92 \\
\hline & 9.87 & 1.16 & 3.96 \\
\hline & 11.8 & 3.17 & 4.49 \\
\hline & 13.8 & 4.59 & 4.82 \\
\hline & 17.1 & 6.92 & 4.92 \\
\hline & 17.3 & 7.09 & 4.84 \\
\hline
\end{tabular}

きな変化が生じなかったものと考えられる。な打 3 成分 系にSRK式を適用して相関を試みたが満足な結果が得ら れなかった．図中の実線は実験値を滑らかに結んだもの である。

$2.3 \alpha$-トコフェロールーエタノール $-\mathrm{CO}_{2} 3$ 成 分 系

この 3 成分系は $\alpha$-トコフェロールとエタノールが完全 
Table 3 Mole fractions of $\alpha$-tocopherol and ethanol in $\mathrm{CO}_{2}$-rich phase for $\alpha$-tocopherol(A)- ethanol(B) $-\mathrm{CO}_{2}(\mathrm{C})$ system at $40^{\circ} \mathrm{C}$ and composition of feed

\begin{tabular}{|c|c|c|c|c|c|c|}
\hline & \multirow[b]{2}{*}{$P[\mathrm{MPa}]$} & \multirow[b]{2}{*}{$y_{\mathrm{A}} \times 10^{4}[-]$} & \multirow[b]{2}{*}{$y_{\mathrm{B}} \times 10^{3}[-]$} & \multicolumn{3}{|c|}{ Feed (mol) } \\
\hline & & & & $n_{\mathrm{A}}$ & $n_{\mathrm{B}}$ & $n_{\mathrm{C}}$ \\
\hline \multirow{3}{*}{ run $I$} & 10.3 & 4.35 & 3.59 & 0.035 & 0.100 & $* *$ \\
\hline & 13.0 & 5.74 & 3.71 & 0.035 & 0.097 & $* *$ \\
\hline & 16.1 & 10.3 & 3.23 & 0.035 & 0.091 & 2.47 \\
\hline \multirow{3}{*}{ run II } & 10.1 & 6.04 & 5.40 & 0.063 & 0.174 & $* *$ \\
\hline & 13.3 & 10.0 & 4.96 & 0.063 & 0.162 & $* *$ \\
\hline & 16.2 & 12.4 & 5.12 & 0.063 & 0.154 & 2.18 \\
\hline
\end{tabular}

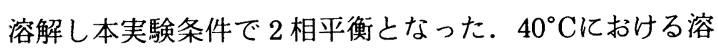
解度デー夕をTable 3 に示し， $\alpha$ ートコフェロール $-\mathrm{CO}_{2}$ 2 成分系の溶解度と比較して Fig. 4 亿示した。

๙ -トコフェロールとエタノールの最初の仕込モル比は ほぼ $1 / 3(16 \mathrm{MPa}$ では $2 / 5$ に変化する) に保ち，2つの 違う総仕込量の混合系 (run I, II) を用いて実験を行っ た。仕込量が少ない場合 (run I), $\mathrm{CO}_{2}$ 高濃度相におけ るエタノール濃度は約 $3.5 \mathrm{~mol} \%$ とほぼ一定となり，仕 込量が多い方 (run II) は約 $5 \mathrm{~mol} \%$ でほぼ一定となった。 図にはこれら 2 通りの仕込量に対する $\alpha$-トコフェロール の溶解度を破線と実線で示した。乙の系に対してもSRK 式は満足な結果を与えないので, 経験的に, エタノール によるエントレーナ効界が $\mathrm{CO}_{2}$ 高濃度相でのエタノール 濃度に比例し, 圧力に依存しないとして次式を得た。

$$
y_{\mathrm{A}}=y_{\mathrm{A}}^{\circ}+1.3 \times 10^{-2} y_{\mathrm{B}}
$$

こてで $y_{\mathrm{A}}, y_{\mathrm{B}}$ はそれぞれ $\mathrm{CO}_{2}$ 高濃度相における $\alpha$ ートコ フェロール, エタノールのモル分率であり， $y_{\mathrm{A}}^{\circ}$ はその温 度, 圧力に扔ける ル分率である。

各run とも最高圧力 $16 \mathrm{MPa}$ で溶解度実験を終了し, この圧力での仕込量ならびに液相での溶解度を両相の容 積を使って計算した。 その結果 run I の場合の液相の組 成は, $x_{\mathrm{A}}=0.21, x_{\mathrm{B}}=0.08, x_{\mathrm{C}}=0.71$ となり, 一方 run II の場合, $x_{\mathrm{A}}=0.20, x_{\mathrm{B}}=0.16, x_{\mathrm{C}}=0.64$ となった. 乙の乙 とから, $\mathrm{CO}_{2}$ 高濃度相での平衡データとあわせて, $40^{\circ} \mathrm{C}$, $16 \mathrm{MPa}$ 付近ではFig. 5-a亿示すような平衡関係が成立 しているあのと考えられる. 図中破線は $\alpha$-トコフェロー ルとエタノールの仕込組成, 一点鎖線はタイラインを示 す. 実線で囲まれた部分は 2 相領域を表わすが, $\mathrm{CO}_{2}$ 低 濃度域についてはわかりやすいように模式的に描いた。 またFig. 5-b は頂点C 付近の拡大図で, 図中の点線は $\alpha$ ートコフェロールー $\mathrm{CO}_{2} 2$ 成分系に打りる同じ条件下で の溶解度を比較のためにプロットした。

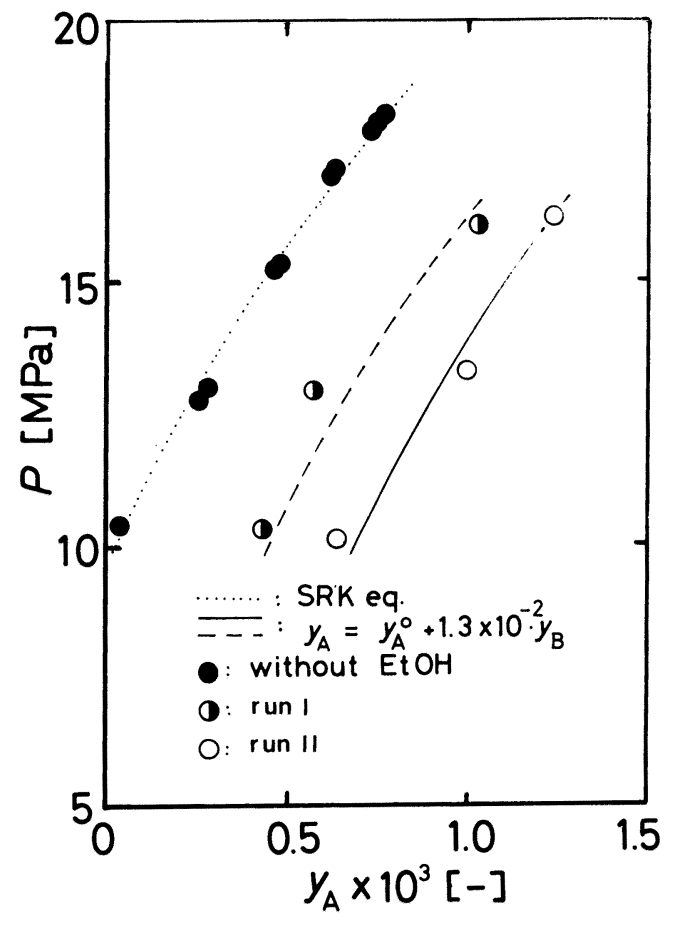

Fig. $4 \quad P$ - $y$ relation of ternary $\alpha$-tocopherol (A) - ethanol (B) $-\mathrm{CO}_{2}$ (C) system at $40^{\circ} \mathrm{C}$

\section{結言}

$\alpha$-トコフェロールー $\mathrm{CO}_{2}$ 系に対して $\mathrm{H}_{2} \mathrm{O}$ を添加した 場合 3 相分䧻を生じ, エントレーナ効果はほとんど確認 できなかった。一方，エタノールをエントレーナとした 場合, 約 $3.5 \mathrm{~mol} \%$ のエタノール添加により純 $\mathrm{CO}_{2}$ 溶媒 への溶解度と比較して, $10 \mathrm{MPa}$ 付近では 10 倍以上, 15 $\mathrm{MPa}$ 付近では 2 倍以上の溶解度となった. てれは $\mathrm{CO}_{2}$ 高濃度相における $\alpha$-トコフェロールの溶解度がエタノー ルの濃度に比例しているてとから, エタノール $-\mathrm{CO}_{2}$ 混 


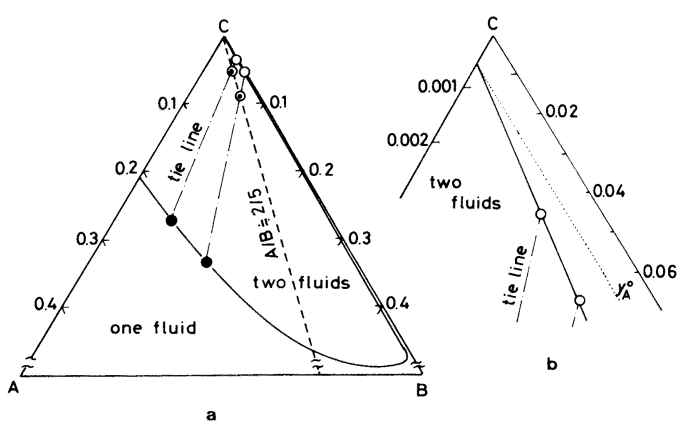

Fig. 5 Phase diagram of $\alpha$-tocopherol(A) -ethanol (B) $-\mathrm{CO}_{2}(\mathrm{C})$ system at $40^{\circ} \mathrm{C}$ and $16 \mathrm{MPa}$

合溶媒の溶媒力が増大したことに起因しているものと考 えられる.

本研究では, 溶媒溶質それぞれに対して不溶解領域を 持つ $\mathrm{H}_{2} \mathrm{O}$ と, 逆に両成分に対して完全溶解するエタノ一 ルをエントレーナとして選んだが，今後溶質成分との間 に不溶解, 溶媒成分には完全溶解するエントレーナや, あるいはその逆の性質を持つエントレーナを使った研究 により，エントレーナ効果の原因……混合流体の溶媒力 と溶質成分の揮発度の変化 ..... についてさらに詳しい情 報が得られるものと考えられる。

[付 記] 本研究は文部省科学技術研究補助金により援助 を受けた。

\section{Nomenclature}

$$
\begin{aligned}
& P=\text { total pressure } \\
& x=\text { liquid mole fraction } \\
& y=\text { mole fraction in carbon dioxide-rich } \\
& \quad \text { phase } \\
& <\text { Subscripts }> \\
& \mathrm{A}=\alpha \text {-tocopherol } \\
& \mathrm{B}=\text { entrainer (water or ethanol) } \\
& \mathrm{C}=\text { carbon dioxide } \\
& \circ \quad=\text { in pure carbon dioxide }
\end{aligned}
$$

\section{Literature cited}

1) Brunner, G. : Fluid Phase Equilibria, 10, 289 (1983)

2) Gopal, J. S., G. D. Holder and E. Kosal : IEC. Proc. Design and Develop., 24, 697 (1985)

3) Holder, G. D. : Fluid Phase Equilibria, 29, 447 (1986)

4) Kurnik, R. T. and R. C. Reid : ibid., 8, 93 (1982)

5) Ohgaki, K., I. Tsukahara and T. Katayama : Kagaku Kogaku Ronbunshu, 10, 372 (1984)

6) Ohgaki, K., K. Semba, I. Tsukahara and T. Katayama : ibid., 13, 298 (1986)

7 ) Soave, C. : Chem. Eng. Sci., 27, 1197 (1972)

8) Wiebe, R. and V. L. Gaddy : J. Am. Chem. Soc., 62, 815 (1940)

\title{
Entrainer Effect of $\mathrm{H}_{2} \mathrm{O}$ and Ethanol on $\alpha$-Tocopherol Extraction by Compressed $\mathrm{CO}_{2}$
}

\author{
Kazunari Ohgaki, Makoto Nishikawa*, Tadashi Furuichi** \\ and Takashi Katayama
}

Dept. of Chem. Eng., Osaka Univ., Toyonaka 560

Key Words : Supercritical Fluid Extraction, Phase Equilibrium, Entrainer, Tocopherol, Carbon Dioxide, $\mathrm{H}_{2} \mathrm{O}$, Ethanol, Solubility

Solubilities of $\alpha$-tocopherol in the $\mathrm{CO}_{2}$-rich phase were measured for $\alpha$-tocopherol $-\mathrm{H}_{2} \mathrm{O}-\mathrm{CO}_{2}\left(10-18 \mathrm{MPa}, 25^{\circ} \mathrm{C}\right.$ and $\left.40^{\circ} \mathrm{C}\right)$ and $\alpha$-tocopherol-ethanol- $\mathrm{CO}_{2}(10-16 \mathrm{MPa}$, $40^{\circ} \mathrm{C}$ ) systems by means of a flow method to investigate the entrainer effect in supercritical fluid extraction.

The solubility of $\alpha$-tocopherol in the ternary $\alpha$-tocopherol- $\mathrm{H}_{2} \mathrm{O}-\mathrm{CO}_{2}$ system was almost the same value as in the binary $\alpha$-tocopherol- $\mathrm{CO}_{2}$ system. In the ternary $\alpha$ tocopherol-ethanol- $\mathrm{CO}_{2}$ system, the solubility of $\alpha$-tocopherol increased proportionally to the concentration of ethanol in the $\mathrm{CO}_{2}$-rich phase.

* Kuraray Co., Ltd.

** Yamatake-Honeywell Co., Ltd. 